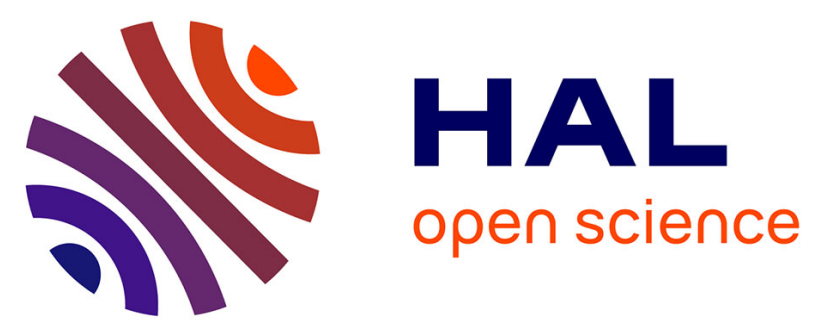

\title{
Flat plate thermal solar collector efficiency: transient behavior Under working conditions Part Ii: Model Application and design contributions
}

\author{
M.C. Rodríguez-Hidalgo, P.A. Rodríguez-Aumente, A. Lecuona, G.L.
} Gutiérrez-Urueta, R. Ventas

\section{To cite this version:}

M.C. Rodríguez-Hidalgo, P.A. Rodríguez-Aumente, A. Lecuona, G.L. Gutiérrez-Urueta, R. Ventas. Flat plate thermal solar collector efficiency: transient behavior Under working conditions Part Ii: Model Application and design contributions. Applied Thermal Engineering, 2011, 31 (14-15), pp.2385. 10.1016/j.applthermaleng.2011.04.002 . hal-00781346

\section{HAL Id: hal-00781346 https://hal.science/hal-00781346}

Submitted on 26 Jan 2013

HAL is a multi-disciplinary open access archive for the deposit and dissemination of scientific research documents, whether they are published or not. The documents may come from teaching and research institutions in France or abroad, or from public or private research centers.
L'archive ouverte pluridisciplinaire $\mathbf{H A L}$, est destinée au dépôt et à la diffusion de documents scientifiques de niveau recherche, publiés ou non, émanant des établissements d'enseignement et de recherche français ou étrangers, des laboratoires publics ou privés. 


\section{Accepted Manuscript}

Title: Flat plate thermal solar collector efficiency: transient behavior Under working conditions Part li: Model Application and design contributions

Authors: M.C. Rodríguez-Hidalgo, P.A. Rodríguez-Aumente, A. Lecuona, G.L. Gutiérrez-Urueta, R. Ventas

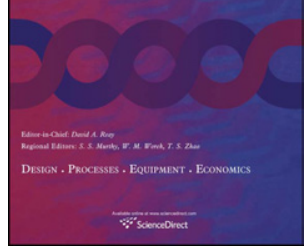

PII:

$$
\text { S1359-4311(11)00190-6 }
$$

DOI: 10.1016/j.applthermaleng.2011.04.002

Reference: $\quad$ ATE 3497

To appear in: $\quad$ Applied Thermal Engineering\#

Received Date: 30 October 2010

Revised Date: 12 February 2011

Accepted Date: 6 April 2011

Please cite this article as: M.C. Rodríguez-Hidalgo, P.A. Rodríguez-Aumente, A. Lecuona, G.L. Gutiérrez-Urueta, R. Ventas. Flat plate thermal solar collector efficiency: transient behavior Under working conditions Part li: Model Application and design contributions, Applied Thermal Engineering (2011), doi: 10.1016/j.applthermaleng.2011.04.002

This is a PDF file of an unedited manuscript that has been accepted for publication. As a service to our customers we are providing this early version of the manuscript. The manuscript will undergo copyediting, typesetting, and review of the resulting proof before it is published in its final form. Please note that during the production process errors may be discovered which could affect the content, and all legal disclaimers that apply to the journal pertain. 


\title{
FLAT PLATE THERMAL SOLAR COLLECTOR EFFICIENCY: TRANSIENT BEHAVIOR UNDER WORKING CONDITIONS
}

\section{PART II: MODEL APPLICATION AND DESIGN CONTRIBUTIONS}

\author{
Rodríguez-Hidalgo, M.C., Rodríguez-Aumente, P.A. * , Lecuona, A., Gutiérrez- \\ Urueta, G.L., Ventas, R.
}

Universidad Carlos III de Madrid. Departamento de Ingeniería Térmica y de Fluidos. Grupo ITEA

Avda. Universidad 30, 28911 Leganés, Madrid, Spain

\begin{abstract}
An experimental research was performed on a solar facility with a nine-year-old, on-campus field with $50 \mathrm{~m}^{2}$ area of flat plate solar collectors. A transient model was developed, adapted to the characteristics of this facility and experimentally validated as described in Part I of this paper.
\end{abstract}

The efficiency normalization curve (ENC) operating conditions for the steady-state test are different from the working conditions. Significant differences between the ENC and the model-based predictions were found and quantified.

The significance of the transient behavior is compared with the thermal inertia proposed in the EN-12975:2006 standard for the quasi-dynamic test.

* Corresponding author: Phone: +34 916249406 Fax: +34 916249430 E-mail: aument@ing.uc3m.es 
Using the model capabilities to predict the collector performance under transient working conditions, the influence of the operating conditions on the collector efficiency and on the useful heat produced is studied individually. The relevance of those conditions is ranked as follows: the wind (velocity magnitude and direction) was the most influential, followed by the aging of the collector surfaces, convective heat losses, thermal inertia and the incident angle of irradiance.

Keywords: Solar energy; Flat plate collector; Transient model; Collector thermal efficiency; Collector performance; Solar Domestic Hot Water.

\section{NOMENCLATURE:}

A: Collector aperture area $\left[\mathrm{m}^{2}\right]$

$a_{1}$ : Collector efficiency normalization curve constant $\left[\mathrm{W} \mathrm{m} \mathrm{m}^{-2} \mathrm{~K}^{-1}\right]$

$a_{2}$ : Collector efficiency normalization curve constant $\left[\mathrm{W} \mathrm{m} \mathrm{m}^{-2}\right]$

c: EN-12975:2006 collector efficiency constant

$E_{L}$ : Long wave irradiation $\left[\mathrm{W} \mathrm{m}^{-2}\right]$

$F^{\prime}:$ Collector efficiency factor $[-]$

$G$ : Solar irradiance $\left[\mathrm{W} \mathrm{m}^{-2}\right]$

I: INERTIA: Thermal inertia [W]

$k_{T}$ : Clearness index $\quad-[-]$

$K_{\theta}$ : Incident angle modifier constant [-]

$P v$ : Partial pressure of water vapor in the ambient wet air [Pa]

$Q:$ Heat power $[\mathrm{W}]$

$T$ : Temperature $[\mathrm{K}]$

$t$ : Time $[\mathrm{s}]$ 
$u$ : Wind velocity $\left[\mathrm{m} \mathrm{s}^{-1}\right]$

\section{ABBREVIATIONS:}

DHW: Domestic Hot Water

ENC: Efficiency Normalization Curve

IAM: Incident Angle Modifier

\section{GREEK:}

$\alpha$ : Absorptance

$\eta$ : Efficiency

$\theta$ : Solar irradiance incident angle

$\xi$ : Wind draft direction relative to the east to west direction

$\sigma:$ Stefan-Boltzmann constant $\left[\mathrm{W} \mathrm{m}^{-2} \mathrm{~K}^{-4}\right]$

$\tau$ : Transmittance

\section{SUBCRIPTS:}

0 : Collector optical efficiency

$a$ : Ambient

$B$ : Beam

$D$ : Diffuse

$e n$ : Effective in the collector normal direction

$m$ : Mean value between the collector inlet and the outlet temperatures

$o$ : Extraterrestrial irradiance

$T:$ Sloped plane

useful: Instantaneous useful power

Z: Horizontal plane 


\section{INTRODUCTION}

To compare various collectors, there are standards for certifying their performance under the same operating conditions. Primarily, the ASHRAE-93:2003 and EN12975:2006 standards [1] and [2], which are enforced in the USA and European countries, respectively.

The EN-12975 standard [2] allows for the testing of the flat plate collector either in steady state (Section 6.1) obtaining the efficiency normalization curve (ENC) or in quasi-dynamic regimes (Section 6.3). Both tests can be performed either outdoors or indoors (in a laboratory room with a solar simulator). Depending on which test is chosen the results show differences, according to [3]. The steady state test leads to the commonly used efficiency normalization curve (ENC), as in Equation 1.

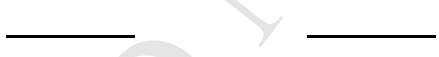

As a consequence, the collector useful heat can be calculated as shown in Equation 2.

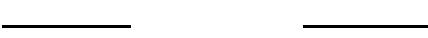

For the quasi-dynamic test, the useful heat is determined using Equation (3), where the relevance of the heat losses due to convection and radiation, as well as the collector thermal inertia, are conditioned to a statistical significance test using a multiple linear regression. As a result, the $T$ ratio (coefficient value over coefficient standard deviation) of the coefficients $c_{3}, c_{4}$ and $c_{6}$ should be larger than 2.0 to be retained in the equation. Meanwhile, the coefficients $c_{1}, c_{2}$ and $c_{5}$ are mandatory. 
It is important to be able to describe the collector performance throughout the whole daytime, with the aim of allowing a right solar facility design and use, as well as the control protocols applied to it. Solar cooling is an application example where an accurate description of the collector instantaneous performance is required. A direct drive of the absorption chiller seems convenient, as Lecuona et al. 2009 [4] shows. In those cases, the transient aspects are decisive in the interaction between the collector and the chiller, with significant impact on the overall performance.

The EN-12975 [2] standard provides the rules for obtaining the ENC, also specified for the quasi-dynamic test. Thus, the main discrepancies, due to different test conditions, can be avoided. These rules are summarized in Table 1.

In various certification laboratories in Europe, the EN-12975 standard test for the ENC determination [2] has been performed outdoors on the same collector model by [5] and [6], which resulted in some differences among the results. Those authors showed that the possible causes for the differences were the measuring errors and diverse apparatus tolerances. The ambient temperature measurement was a significant source of inaccuracy for the sunny days, and this error propagated to the calculation of the sky temperature. To avoid wind velocity magnitude and direction quantifying errors, they suggested the use of a set of fans to maintain the velocity between 2 and $4 \mathrm{~m} \mathrm{~s}^{-1}$ parallel to the collector surface. The cold water supply temperature was another source of discrepancies among laboratories, [5] and [6]. Furthermore, human errors may have also 
been present due to the singular personnel operational procedures during the testing. Finally, they commented that although the collector efficiency discrepancies from the same laboratory were not significant, the discrepancies in the results of the different laboratories ranged from $5 \%$ to $10 \%$ among the laboratories located in warm and cold climates. They were attributed to the length of the day and the cold water supply temperature control. From that study, it was concluded that the ENC is sensitive to the operating conditions.

The transient model was developed and experimentally validated in Part I of this paper, [7]. It provides the description of the collector efficiency under actual outdoor working conditions.

As a summary, the primary objectives of this paper are listed as follows:

To test the capability of the model for describing the collector efficiency under different working conditions from the ones used for its calibration. For that, the EN-12975 standard [2] specific operating conditions were sequentially imposed on the model. The efficiency of the collector is then compared to the ENC.

The significance of the transient behavior, which is described in the model as thermal inertia, is compared with the thermal inertia proposed in the EN-12975 standard [2] for the quasi-dynamic test with the goal of proving the capability for the model to describe the collector efficiency under transient conditions. This study focuses on an analysis of the $c_{5}$ coefficient.

A sensitivity analysis of the meteorological conditions on the collector efficiency has been also performed. This study is not based on the application of the EN-12975 
standard [2] operating conditions; rather, it is based on the direct application of the transient model that was described in Part I of this paper, [7]. The meteorological data corresponding to the year under consideration was the input into the model. The most relevant effects, such as collector aging, wind convective heat losses, irradiance incidence angle, thermal inertia and radiation losses were then separately cancelled to evaluate their global effects, which allows for a determination of the collector performance sensitivity to each of these effects.

The results obtained from this sensitivity study are applied to the solar facility sizing, which demonstrates that the calculated collector absorption surface requires significant modifications if the above-described conditions are varied.

\section{FROM EXPERIMENTAL TO EFFICIENCY NORMALIZATION CURVE} (ENC)

The experimental facility is described in Part I [7] and in detail in [18]. It consists on a field of nine-year-old flat plate thermal collectors of the model Vitosol 100 w2.5 by Viessmann Werke $\mathrm{GmbH}$ and $\mathrm{Co} \mathrm{KG}^{\circledR}$, having a total absorbing surface of $50 \mathrm{~m}^{2}$. They were located on a 4-story building horizontal terrace and consisted of four rows of six, six, five and three collectors each, which were operated under steady-state flow conditions. They were facing south with a surface azimuth angle of 11 degrees east and they sloped at an angle of 40 degrees, which corresponds to the local latitude (Madrid, Spain). They were dedicated to the production of domestic hot water (DHW). The time period studied was from 2008-02-27 to 2009-02-26, and the time step for data acquisition was 10 minutes. The solar collectors field pump operated each day from 07:00 to 22:00 (official time) hours, by continuously moving a water flow rate of 
$0.610^{-3} \mathrm{~m}^{3} \mathrm{~s}^{-1}\left(0.310^{-4} \mathrm{~m}^{3} \mathrm{~s}^{-1}\right.$ per collector $)$. This working schedule did not consider pump interruptions due to cloudy periods, but it allowed for the collection of working data under all the meteorological conditions throughout the year on a consistent time basis.

The ENC operating conditions were sequentially recovered by modifying the input data to the model and are referred to in this paper as the 'ENC model application'. These input data correspond to an entire year. Figure 1 shows the conditions throughout a representative day (2009-01-20). This day was chosen for the strong variability of the meteorological conditions. Figure $2 \mathrm{~A}$ shows the instantaneous $\mathrm{ENC}$ from the experimental — collector mass flow rate and the temperature increase, and the model efficiency, all three for the entire year. Figure $2 \mathrm{~B}$ shows the temporal variation of the three efficiencies previously described for the representative day. The model efficiency is close to the experimental efficiency but not the ENC.

\subsection{Optical efficiency}

Hereafter, the bolded type in the subsection titles indicates the parameter that was modified from the actual value to the standard one, or the effects that were considered from the actual step and in the following steps.

The EN-12975 standard [2] test is typically performed on a brand new solar thermal collector. According to the Institut für Solartechnik SPF, the collector under study has a value of $\eta_{0}=0.85$ if it is new. As shown in Figure 3, the experimentally determined value has diminished to 0.76 after nine years of operation. The optical efficiency 
parameter was obtained from the experimental data whose working conditions were the same as in EN-12975. Thus, the first change to apply for recovering the ENC is the recovery of the value if the collector were brand new. The sensitivity to this parameter is studied in more detail in Section 3.

\section{2}

and incident angle modifiers

The incident angle modifier (IAM) constant values were defined for each of the irradiance components following [8], and their values depend on the incident angle, as previously discussed in Part I of this paper, [7].

The collector ENC test can be performed either outdoors or indoors. In both tests, the solar irradiance is specified as nearly perpendicular to the collector surface. Consequently, $K_{\theta}$ for both the beam and the diffuse irradiance components reached the maximum value, as shown in Table 1. If they are implemented in the model, these ENC $K_{\theta}$ values result in a collector efficiency that is shown in Figure 4. The net result is that the collector efficiency is overestimated near the sunrise and sunset because of the large incidence angle. With respect to the radiation direction, the actual operating conditions were significantly different from the ENC test conditions.

\section{3}

\section{thermal inertia effect removed}

Thermal inertia is one of the key factors that is considered in the EN-12975 [2] quasidynamic test. Nonetheless, when determining the collector ENC, this effect is not taken into account because it is a steady-state test, as explained in Part I of this paper [7]. Removing the thermal inertia of the collector components from the model leads to an 
efficiency evolution throughout the day with a shape that is similar to the ENC, as shown in Figure 5. losses to the ambient, is prescribed at a constant value of $100 \mathrm{~W} \mathrm{~m}^{-2}$. This is so independently of the type of collector, ambient temperatures and surface emissivity. Figure 6 shows the effect of imposing this value in the collector efficiency calculation throughout the model. As a result, the radiation losses are overestimated in the collector ENC for the working conditions that were considered.

; thermal inertia effect removed,

$$
\text { and }
$$
parallel to collector surface.

The magnitude of the wind velocity results in a large variation in an actual collector field, as discussed in Part I of this paper [7]. The wind velocity changes not only in the free field but also at the external collector surfaces due to interactions between the collector rows and the building envelope.

The effect of the wind velocity on the efficiency was implemented in the collector model, and the results are shown in Figure 7. To demonstrate the effects of wind related losses, the representative day was considered, as it was a breezy day with a maximum wind velocity of $6 \mathrm{~m} \mathrm{~s}^{-1}$, as shown in Figure 1. That day showed no preferential direction. 
The results from the application of the EN-12975 standard [2] values into the model are also shown in Figure 7. The model accurately described the ENC for the single-day time variation.

\subsection{All the effects considered.}

Figure 7 shows the results from the introduction of all the EN-12975 [2] operating conditions for the entire year in the 'ENC model application'. The results can be considered of high accuracy.

The objective of proving the collector model applicability to the different working conditions starting from the conditions corresponding to its experimental validation can be considered successfully reached. A statistical study yields an average difference between the 'ENC model application' and the ENC of $0.002 \%$, and the confidence interval at $95 \%$ probability is $\pm 1.8 \%$ for the whole year.

\section{TRANSIENT MODEL CHARACTERISTIC}

The determination of the instantaneous thermal collector efficiency under transient working conditions requires considering the thermal inertia of all of the components of the collector. The existing literature offers several methodologies to describe the transient performance of solar collectors, and some relevant examples are [9] to [17]. In these studies, the components that are most accounted for are the inner water fluid, the absorber plate, the glass cover and the insulation sheet, which is typically accomplished by calculating the thermal inertia based on the water temperature-time variations. In this study, the thermal inertia is modeled for these four components and for the layer of air between the glass cover and the absorber plate, the serpentine tube, the two fluid 
distributor tubes and the box back surface. For the evaluation of the inertia, each component was considered to have its own temperature variation.

If the thermal inertias of the collector components were not considered, the collector efficiency would be overestimated by a mean value of $3.2 \%$. Figure 8 shows the effects of this operating condition. The value of the thermal inertia changed from positive in the morning, when the temperature of the collector components increased, to negative in the evening, when the temperature of the collector components decreased. These results imply that the collector efficiency was overestimated or underestimated, depending on the time of the day. The instantaneous thermal inertia represents a maximum value of $60 \%$ of the maximum instantaneous collector useful heat value. Then, the evaluation of instantaneous collector useful heat does require an accurate calculation of thermal inertias. As an example, the direct application of a solar plant to produce cooling energy: in case the thermal inertia is not taken into account the absorption chiller could be fed with a thermal energy higher than the one it can process. Therefore, this produces an increase of the collector temperature and a decrease in the efficiency of the collectors and consequently, this leads to a decrease of the efficiency of the whole system.

The quasi-dynamic test of the EN-12975 standard [2] contains the rules to calculate the inertia using the $c_{5}$ coefficient in Equation (3). The thermal capacitance must be calculated by considering the absorber plate, water, insulation and glass cover. The last two components have to be weighted with a coefficient of 0.5 and $0.01 \times a_{1}$, respectively. The temporal variation of the water temperature is attributed to the four components. The application of these rules yields $c_{5}=10.3 \mathrm{~kJ} \mathrm{~K}^{-1} \mathrm{~m}^{-2}$ for the solar collector used. 
The model uses different temperatures for each of the collector components. This way the total thermal inertia of the collector is determined from the model results. Dividing this total value by the temporal variation of the temperature of the water inside the collector, an instantaneous value for an equivalent $c_{5}$ constant is obtained. Its timeaveraged value corresponds to $20.4 \mathrm{~kJ} \mathrm{~K}^{-1} \mathrm{~m}^{-2}$ for the daily-integrated data throughout the year.

By modeling only the thermal inertia of the four components that the EN-12975 standard [2] prescribes, i.e. the inner water, the absorber, the glass cover and the insulation, the "internal inertia" was obtained. Their values are shown in Figure 9.

Comparing this internal inertia with the value of the EN-12975 standard [2] (i.e. $c_{5}=10.3$ $\mathrm{kJ} \mathrm{K}^{-1} \mathrm{~m}^{-2}$ ) as shown in Figure 9, similar results were obtained. However, the collector total inertia exhibits a larger amount of variability throughout the day.

Table 2 shows the contribution of each component to the $c_{5}$ constant value. The glass cover contribution was underestimated by the EN-12975 standard [2], and the inner water was responsible for the largest contribution. For our case, it included the inner piping, which is supposed to exhibit the same temperature variation as the water. The contribution of the inner water was followed in importance by the insulation. The model included a more accurate description of the glass cover and box back surface inertias due to the use of the specific temperature variations for each component, and both of the inertias were of appreciable magnitude. 


\section{ANALYSIS OF SENSITIVITY TO THE WORKING PARAMETERS}

As shown above, the model was able of accurately predicting the collector efficiency for diverse operating conditions, including transient conditions, see Figure 9.

In this section, it will be applied for the quantification of the different effects on the collector efficiency. Each effect will be suppressed in the model, and the resulting useful heat will be integrated throughout the studied year to find the differences between it and the useful heat obtained from the model that accounted for all of the effects. It should be noted that the meteorological conditions were variable along the studied year, which promoted the variability that is shown in the following figures.

\subsection{Aging}

The collector aging had one of the most significant effects on the performance. In this study, the collector field was nine-year-old, around half the operative life, and the optical efficiency diminished by $9 \%$, from 0.85 to 0.76 . This included the effect of dust and dirt over the glass cover. Further studies should be performed to describe the aging time-evolution.

As shown in Figure 10, the collector efficiency was overestimated by a significant magnitude if the collector aging was not taken into account. For our case, the influence of aging in the one-year integrated useful heat represents a relative loss of $15.0 \%$.

\subsection{Wind convective heat losses}

To reduce the uncertainties in quantifying the wind velocity magnitude and direction, the EN-12975 test specifies a constant value of 2 to $4 \mathrm{~m} \mathrm{~s}^{-1}$ parallel to the collector 
surface without specifying neither the direction nor the turbulence intensity. However, the actual collector field is subjected to the entire range of wind velocity directions and magnitudes. As previously discussed in Part I of this paper [7], the model used the wind velocity magnitude and direction on the atmospheric free flow, primarily due to two reasons. On one hand, this type of data corresponds to the information that meteorological databases commonly provide; also, they correspond to the parameters that could be measured by a monitoring meteorological station dedicated to the facility. On the other hand, it attempts to avoid the complex determination of the wind interaction with the collector rows and the building envelope, which would be needed in the case of a model based on the velocity near the collector surface. The drawback is a loss of generality.

To quantify the effects that the wind velocity had on the collector efficiency, the consideration of a null wind velocity was implemented in the model; then, only freely convecting heat transfer was retained in the collector efficiency calculation. Figure 11 shows that the efficiency is overestimated. The influence of the wind convective heat losses represents a relative loss of $15.6 \%$ in the collector efficiency from the integration of the data of the entire year. An average wind velocity of $2.3 \mathrm{~m} \mathrm{~s}^{-1}$ along the studied year was measured for the time interval when the pump was working.

Consequently, a more detailed model of the convective heat losses seems of high interest. Then, a range of wind velocity magnitudes from 1 to $11 \mathrm{~m} \mathrm{~s}^{-1}$ and wind directions from $90^{\circ}$ (perpendicular to the collector edge in the horizontal plane) to $180^{\circ}$ (parallel to collector surface) was considered for illustrative purposes. Figure 12 shows the regression values of the actual collector efficiency for this range. Figure 12 depicts 
some experimental measurements that were taken at the same operating conditions as the simulated ones, allowing observing how the model implements the wind velocity magnitude and direction. The collector efficiency decreases with the magnitude of the wind velocity. The direction of the wind affects also the efficiency; the parallel direction results in a better efficiency for the same wind velocity magnitude.

\subsection{Irradiance incidence angle}

If the value of $K_{\theta B}$ is considered to be equal to the constant maximum value $K_{\theta B}=1$ in the determination of the absorbed energy, then the collector efficiency is overestimated by a relative mean value of $7.6 \%$ as shown in Figure 13 . A correction based on the instantaneous value of $K_{\theta B}$ is required to accurately describe the collector performance throughout a complete solar day in working facilities.

\subsection{Radiation losses}

Radiation losses depend on the long wave emissivity and temperature of the glass as well as on the sky temperature, which results in a variable value throughout the day.

The external radiation losses were modeled by considering that the glass cover temperature was higher than the sky temperature. For the model, the sky temperature was calculated as described in Part I of this paper [7].

For the case in which the actual external radiation losses were not considered, the model predicted a collector efficiency that was overestimated by a mean value of $1.3 \%$ for the daily integrated data throughout the year. Figure 14 shows this effect. 
Table 3 summarizes the collector efficiency sensitivity to the different individual effects that were analyzed in this study.

\section{CONTRIBUTIONS TO SIZING AND DISCUSSION}

The collector field surface required to fulfill the demand for the DHW application was estimated from ENC based calculations to be of $40 \mathrm{~m}^{2}$. Nevertheless, the calculation based on experimental data led to $50 \mathrm{~m}^{2}$. Nominally, the solar facility attends $60 \%$ of the yearly DHW demand from a building of 47 apartments with 188 inhabitants. This is according to the Código Técnico de la Edificación (2006), which is part of the Spanish code for buildings.

This increase in the surface is due to the previously studied effects, and they are described by the following: considering the convective losses due to wind resulted in a $6.5 \mathrm{~m}^{2}$ increase in the total surface needed, and consideration of the aging factor resulted in a $5.4 \mathrm{~m}^{2}$ increase. Considering the actual IAM value increases the surface by $1.5 \mathrm{~m}^{2}$. Considering the actual external radiation losses instead of a constant value of $100 \mathrm{~W} \mathrm{~m}^{-2}$ decreased the surface by $2.1 \mathrm{~m}^{2}$, and considering the actual thermal inertia increased the surface by $1.7 \mathrm{~m}^{2}$.

For the convective losses, aging and inertia, the surface increment was due to the simplifications of the EN-12975 standard [2] in calculating the ENC. The decrease in the surface due to radiation losses corresponds to an overestimation of these losses. For the case of the IAM, the actual collector incident irradiance is not always normal to its surface, as the EN-12975 standard [2] considers for the test. An accurate evaluation of the transient effects in the collector field shows higher instantaneous useful heat values that could saturate the system directly driven by it. For this reason, the system should be oversized by around a $60 \%$. 
The EN-12975 standard imposes strong requirements on the hemispheric global irradiance that is incident to the collector surface. Actually, this standard can only be applied for the outdoor ENC determination during midday $\pm 1 \mathrm{~h}$ and only for days when solar irradiance is greater than $1,000 \mathrm{~W} \mathrm{~m}^{-2}$, as discussed in Section 6.3.4.8.4 of the standard. In the Madrid region, this opportunity occurs for only about 80 days during the summer season. This short time is the reason why the direct application of the ENC to predict the actual working performance of a collector field results in a substantial loss of accuracy, both throughout the day and annually.

\section{CONCLUSIONS}

Relative to the EN-12975 steady-state test (ENC), the following conclusions can be drawn:

- The model developed has been applied to calculate the collector efficiency under actual working conditions. The results of the ENC were always higher, which was mainly due to the differences in the operating conditions of the ENC test and the actual working conditions.

- If the same conditions of the collector ENC test were input into the model, the same results were obtained. This supports the validity of the model.

Relative to the EN-12975 quasi-dynamic test:

- The value of the inertial coefficient $c_{5}$ was recalculated with the model, taking into account all of the collector components and their respective temperature-time increments. This resulted in a value of the thermal inertia that was larger than the standard recommended value. The contribution of some components, namely: glass 
cover, box back surface and insulation to the thermal inertia have shown to be significant.

Relative to the sensitivity analysis:

Once the model prediction capabilities were experimentally checked, it was used to quantify the different effects on the collector average efficiency for both the daily and annual data:

- The influence of each effect on the collector annual average efficiency was studied, and the most significant effects were the wind losses (-15.6\%) and the collector aging $(-15.0 \%)$. The remaining effects consisted of the following, in order of importance: (IAM -7.6\%), thermal inertia $(-3.2 \%)$, but instantaneously it ranged from $-60 \%$ in the morning to $+30 \%$ in the evening, and external radiation losses $(-1.3 \%)$.

- Consideration of the thermal inertia effects causes the need of using oversized systems directly connected to the solar field.

- A study was performed to determine the influence of the wind velocity and direction. It showed that, as the free field wind velocity increases within the normal ranges found during testing and the wind direction is more perpendicular to the collector edge in the horizontal plane, the collector efficiency decreases in an appreciable amount.

Relative to the contributions to sizing of a DHW facility:

- The important factors are the same that affect efficiency excepting thermal inertia, because it results in an increase and a later decrease during the day that almost cancel. The remaining factors imply significant changes in the required area. 


\section{ACKNOWLEDGMENTS}

This work was partially funded by the Spanish government research grant M. C. T. CLIMABCAR project DPI 2003-01567, MINICON project (FIT 0204-2004-68 and FIT 020100-2003-233) and SACSCC project (ENE 2007-63965). Their contribution is greatly appreciated.

\section{REFERENCES}

[1] ASHRAE_93: 2003 Methods of testing to determine the thermal performance of solar collectors. Atlanta: ASHRAE.

[2] UNE:EN-12975:2006 Sistemas solares térmicos y componentes. Captadores solares. Madrid: Asociación Española de Normalización (AENOR), Depósito Legal: M 52090-2006

[3] Rojas D., Beermann J., Klein S.A., Reindl D.T., 2008. Thermal performance testing of flat-plate collectors. Solar Energy 82, 746-757

[4] Lecuona A., Ventas R., Venegas M., Zacarías A., Salgado R. 2009 Optimum hot water temperature for absorption solar cooling. Solar Energy, Volume 83, Issue 10, October, Pages 1806-1814

[5] Bourges, B., A. Rabl, B. Leide, M. J. Carvalho, M. Collares-Pereira. 1991 Accuracy of the European solar water heater test procedure. Part I: measurement errors and parameter estimates. Solar Energy 47, 1-16.

[6] Bourges, B., A. Rabl, M. J. Carvalho, M. Collares-Pereira. 1991 Accuracy of the European solar water heater test procedure. Part 2: prediction of long-term performance. Solar Energy 47, 17-25. 
[7] Rodríguez-Hidalgo M.C., Rodríguez-Aumente P., Lecuona A., Gutierrez-Urueta G.L., Ventas R. 2010 Flat plate thermal solar collector efficiency: transient behavior under working conditions. Part I: Model description and experimental validation. Applied Thermal Engineering

[8] Duffie, J. A., Beckman, W.A. Solar Engineering Thermal Processes. USA: John Wiley and Sons, 2006

[9] Kamminga, W. 1984 Experiences of a solar collector test method using Fourier transfer functions. International Journal of Heat and Mass Transfer 28, 13931404.

[10] Emery, M., Rogers B.A. 1984 On a solar collector thermal performance test method for use in variable conditions. Solar Energy 33, 117-123.

[11] Kamminga, W. 1985 The approximate temperatures within a flat-plate solar collector under transient conditions. International Heat and Mass Transfer 28, 433-440.

[12] Hawlader, M.N.A., Wijeysundera N.E. 1987 Solar collector testing. Renewable Energy Review Journal 9, 11-28

[13] Wang, X.A., Xu Y.F., Meng X.Y. 1987A filter method for transient testing of collector performance. Solar Energy 38, 125-134.

[14] Chungpaibulpatana, S., Exell R.H.B.1988 The effect of using a one node heat capacitance model for determining solar collector performance parameters by transient test methods. Solar Wind Technology 5, 411-421. 
[15] Chungpaibulpatana, S., Exell R.H.B. 1990 Transient method for testing flatplate solar collectors. Energy and the Environment into the 1990`s. Oxford Pergamon Press, 699-703.

[16] Sourproun, A.V. 1992 Dynamic method of solar collector testing. ASME J. Solar Energy Engineering, 2, 1149-1154

[17] Perers B. 1997 An improved dynamic solar collector test method for determination of non-linear optical and thermal characteristics with multiple regression. Solar Energy, 59, 163-178

[18] Rodríguez Hidalgo, M.C., Rodríguez Aumente P., Izquierdo Millán M., Lecuona Neumann A., Salgado Mangual R., 2008 Energy and carbon emission savings in Spanish housing air-conditioning using solar driven absorption system. Applied Thermal Engineering 28, 1734-1744. 
Figure 1: Total solar irradiation for a $40^{\circ}$ sloped plane (collector slope) and the wind velocity on the free field throughout the representative day (2009-01-20).

Figure 2: Efficiency of the collector: 'ENC' for ENC, 'Exp eff' for experimental and 'Mod eff' for model, for the entire 2009 year data every 10 minutes (above) and for the central part of the representative day, 2009-01-20 (below).

Figure 3: Efficiency of the collector: 'ENC' for ENC, 'Mod eff' for the model and 'ENC model application' for the recovery of the brand new optical efficiency: , for the central part of the representative day (2009-01-20).

Figure 4: Efficiency of the collector: 'ENC' for ENC, 'Mod eff' for the model and 'ENC model application' for the recovery of the values:

$$
\text { , for the central part of the representative day (2009-01-20). }
$$

Figure 5: Efficiency of the collector: 'ENC' for ENC, 'Mod eff' for model and 'ENC model application' for the recovery of the values: and thermal inertia effect, removed for the representative day (2009-01-20).

Figure 6: Efficiency of the collector: 'ENC' for ENC, 'Mod eff' for model and 'ENC model application' for the recovery of the values:

, thermal inertia effect removed and radiation losses

for the central part of the representative day (2009-01-20).

Figure 7: Efficiency of the collector: 'ENC' for ENC, 'Mod eff' for model and 'ENC model application' for the recovery of the values:

, thermal inertia effect removed and

a wind direction parallel to the collector surface for the central part of the representative day, 2009-01-20 (above). Working conditions that correspond to an entire year were applied (below).

Figure 8: Comparison between the model efficiency as 'MOD eff' and the model efficiency without the thermal inertia effect as 'Inertia eff', applied to the entire year of meteorological data.

Figure 9: Collector thermal inertia time evolution: for the application of EN-12975:2006 as 'EN-12975 INERTIA', for the model application with all the components as 'TOTAL INERTIA' and including only the absorber plate, inner water and insulation as 'INTERNAL INERTIA', for the central part of the representative day (2009-01-20).

Figure 10: Comparison between the model efficiency without the aging effect as 'aging eff' and the model efficiency as 'MOD eff', applied to the entire year of meteorological data.

Figure 11: Comparison between the model efficiency as 'MOD eff' and the model efficiency without the wind velocity effect as 'Wind eff', applied to the entire year of meteorological data. 
Figure 12: Collector efficiency variation with wind velocity magnitude and direction. The efficiency was calculated by introducing the specified wind magnitude and direction into the model for an actual point with

and $\quad$. The dots represent the actual data as 'EXP'.

Figure 13: Comparison between the model efficiency as 'MOD eff' and the model efficiency without the IAM effect as 'IAM constant eff', applied to the entire year of meteorological data.

Figure 14: Comparison between the model efficiency as 'MOD eff' and the model efficiency without the radiation losses effect 'Radiation losses eff', applied to the entire year of environmental data.

Table 1: EN-12975:2006 parameters for collector efficiency ENC curve calculation under steady state conditions.

Table 2: Contribution to the $c_{5}$ constant for thermal inertia by each component by applying the EN-12975:2006 standard and the model. The percentages show the fraction of the thermal capacitance of each component by considering a unique temperature variation in the inner water flowing inside the collector.

Table 3: Reduction in the annual collector efficiency for excluding each effect independently. 


\begin{tabular}{|c|c|}
\hline Optical efficiency & New collector value: $\eta_{0}=0.85$ \\
\hline IAM beam component of solar irradiance & $K_{\theta B}\left(\theta_{B}\right)=1$ \\
\hline IAM diffuse component of solar irradiance & $K_{\theta D}\left(\theta_{D}\right)=0.82$ \\
\hline Without thermal inertia & $\frac{d T_{m}}{d t}=0$ \\
\hline Radiation thermal losses & $\left(E_{L}-\sigma T_{a}{ }^{4}\right)=100 \mathrm{~W} \mathrm{~m}^{-2}$ \\
\hline Wind draft magnitude & $u=3 \mathrm{~m} \mathrm{~s}^{-1}$ \\
\hline Wind draft direction & Parallel to the collector surface \\
\hline
\end{tabular}

Table 1: EN-12975:2006 parameters for collector efficiency ENC curve calculation under steady state conditions. 


\begin{tabular}{|c|c|c|}
\hline & EN-12975:2006 & MODEL \\
\hline Glass cover & $0.03 \%$ & $3.1 \%$ \\
\hline Inner air layer & -- & $0.12 \%$ \\
\hline Absorber, serpentine and \\
distributor tube
\end{tabular}

Table 2: Contribution to the $c_{5}$ constant for thermal inertia by each component by applying the EN-12975:2006 standard and the model. The percentages show the fraction of the thermal capacitance of each component by considering a unique temperature variation in the inner water flowing inside the collector. 


\begin{tabular}{|c|c|}
\hline Effect & Reduction on collector efficiency \\
\hline Wind losses & $15.6 \%$ \\
\hline Aging (nine years) & $15.0 \%$ \\
\hline Incidence angle & $7.6 \%$ \\
\hline Thermal inertia & $3.2 \%$ \\
\hline Radiation losses & $1.3 \%$ \\
\hline
\end{tabular}

Table 3: Reduction in the annual collector efficiency for excluding each effect independently. 


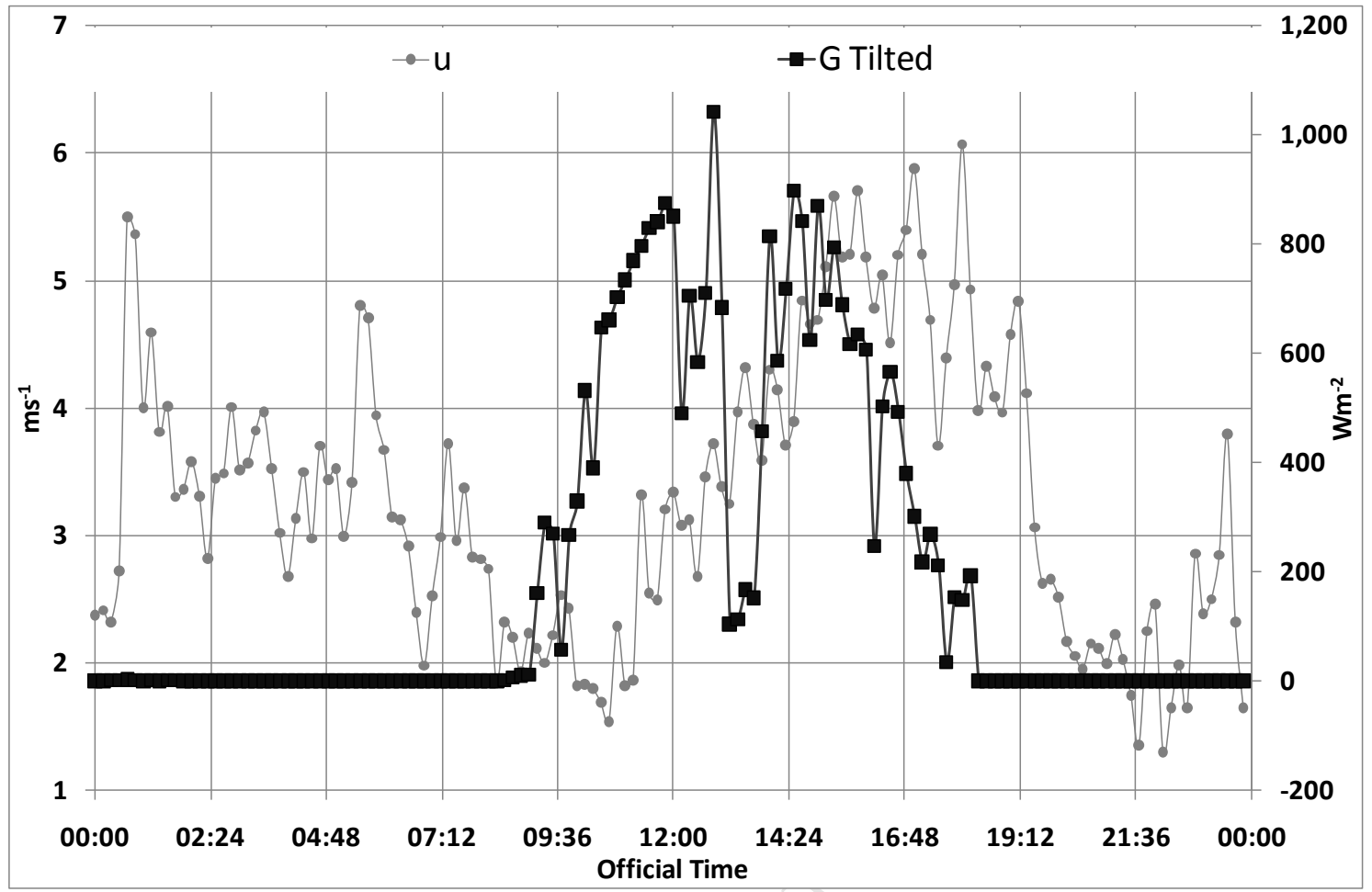

Figure 1: Total solar irradiation for a $40^{\circ}$ sloped plane (collector slope) and the wind velocity on the free field throughout the representative day (2009-01-20). 

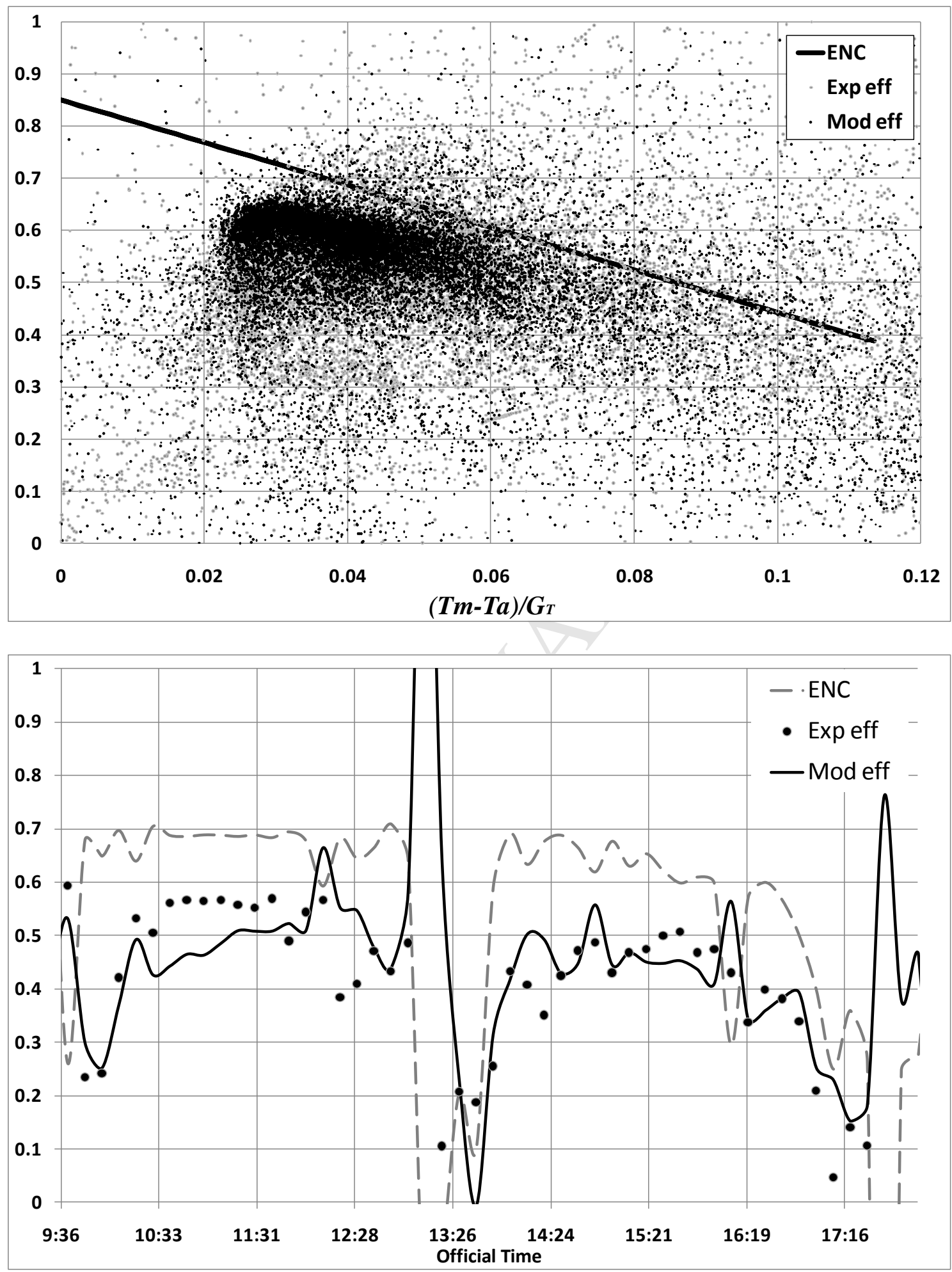

Figure 2: Efficiency of the collector: 'ENC' for ENC, 'Exp eff' for experimental and 'Mod eff' for model, for the entire 2009 year data every 10 minutes (above) and for the central part of the representative day, 2009-01-20 (below). 


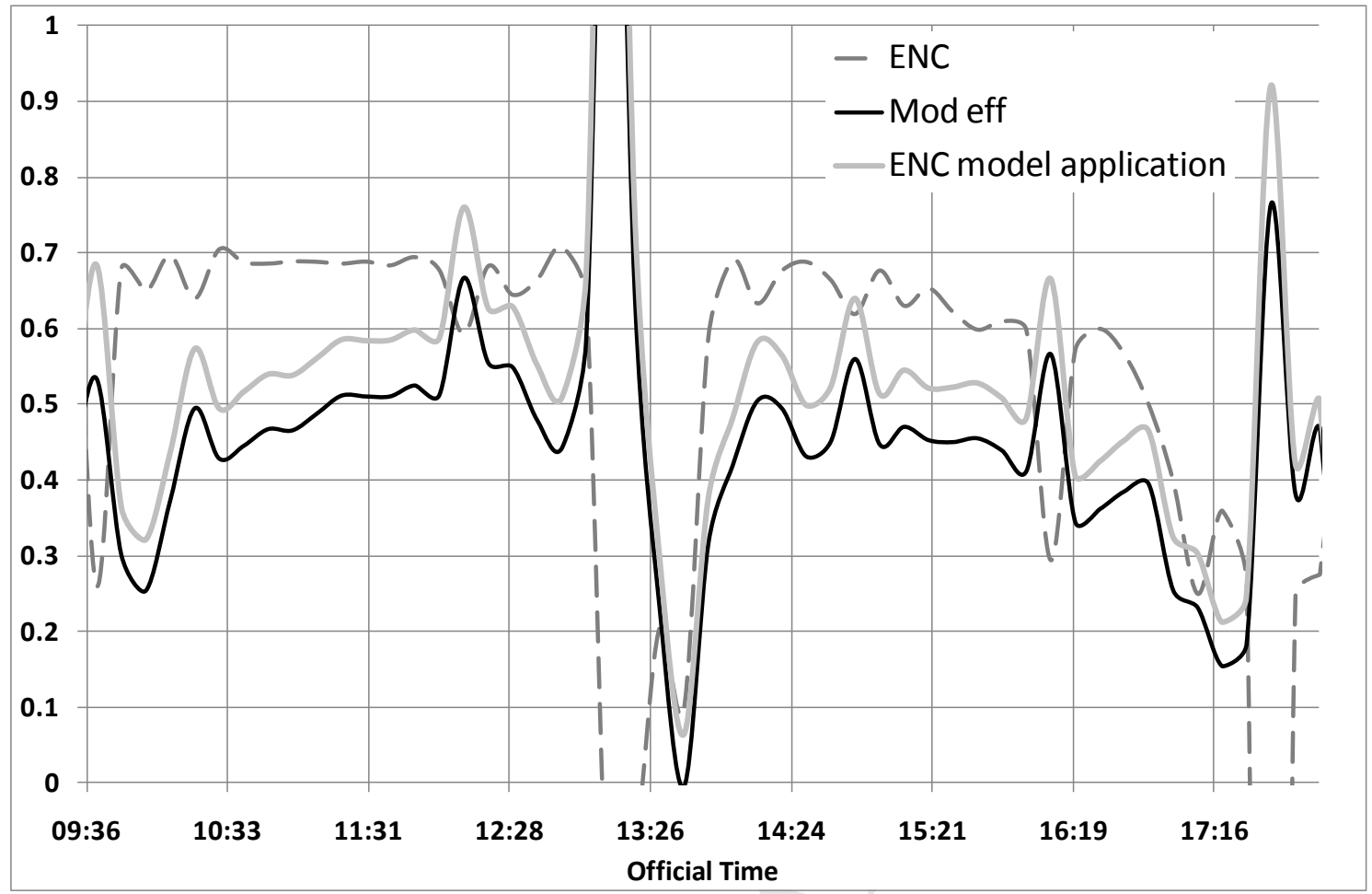

Figure 3: Efficiency of the collector: 'ENC' for ENC, 'Mod eff' for the model and 'ENC model application' for the recovery of the brand new optical efficiency: $\eta_{0}=$ 0.85, for the central part of the representative day (2009-01-20). 


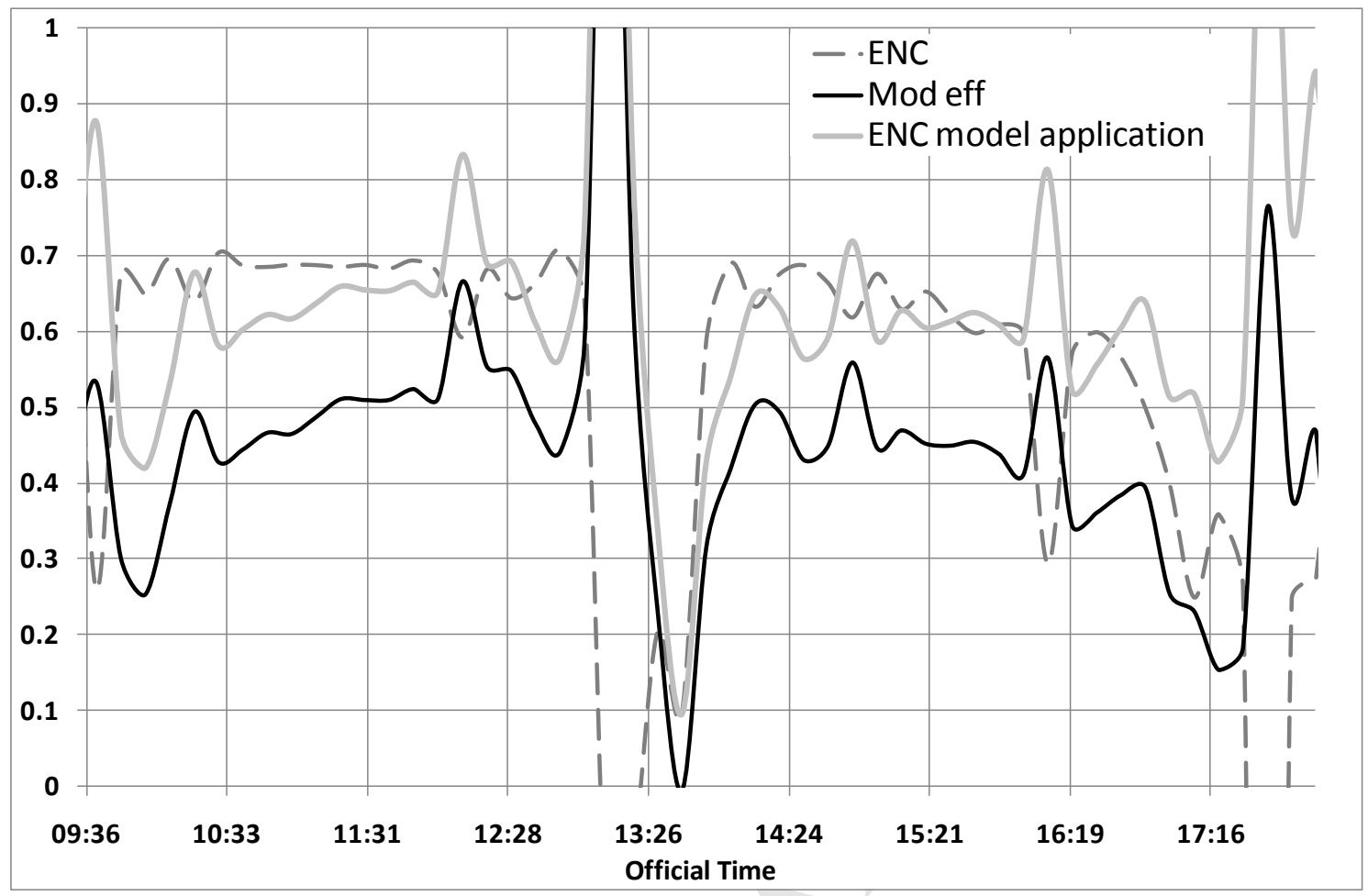

Figure 4: Efficiency of the collector: 'ENC' for ENC, 'Mod eff' for the model and 'ENC model application' for the recovery of the values: $\eta_{0}=0.85, K_{\theta B}\left(\theta_{B}\right)=1$, $K_{\theta D}\left(\theta_{D}\right)=0.82$, for the central part of the representative day (2009-01-20). 


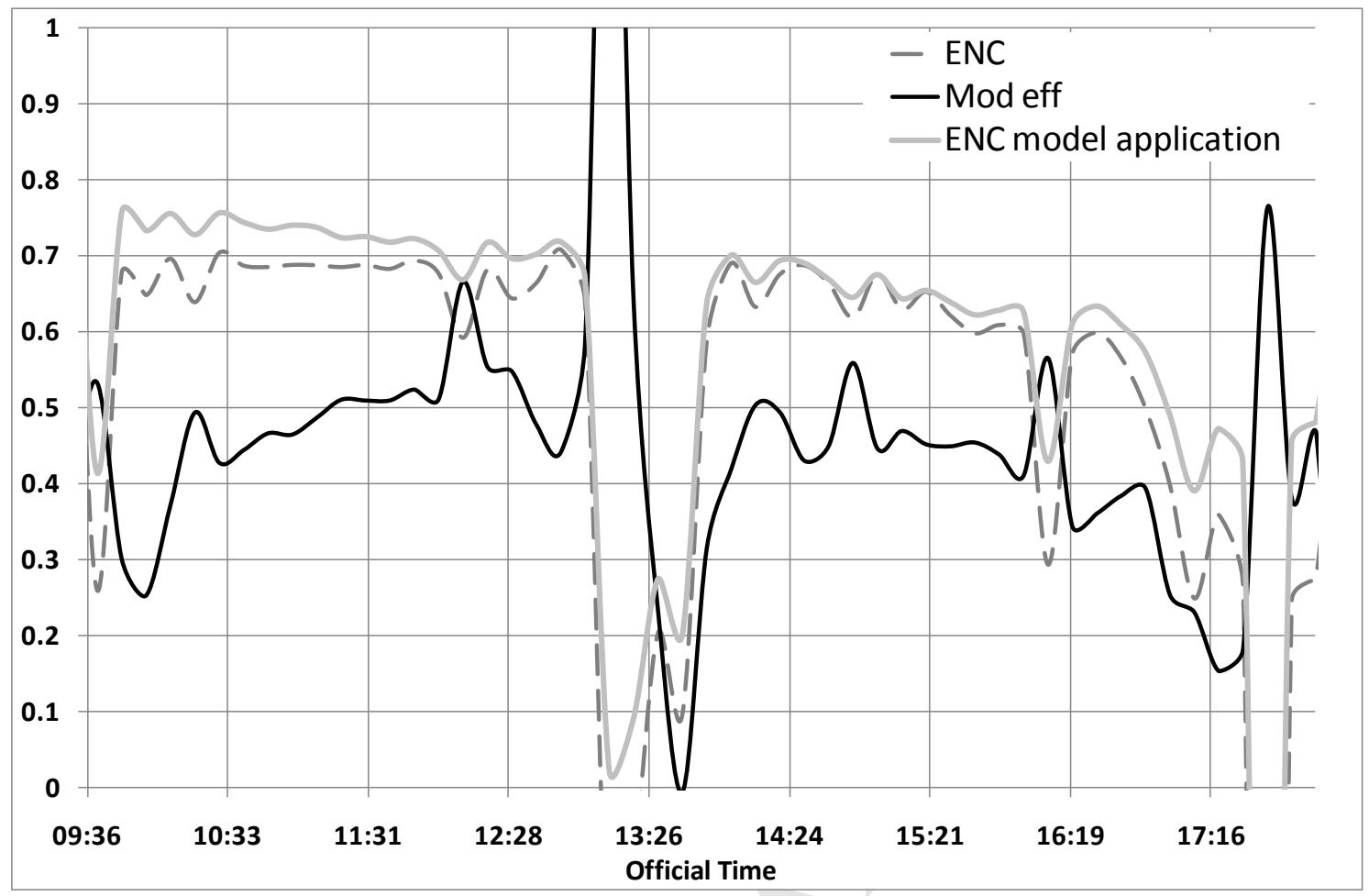

Figure 5: Efficiency of the collector: 'ENC' for ENC, 'Mod eff' for model and 'ENC model application' for the recovery of the values: $\eta_{0}=0.85, K_{\theta B}\left(\theta_{B}\right)=1, K_{\theta D}\left(\theta_{D}\right)=$ 0.82 and thermal inertia effect removed, for a representative day 2009-01-20. 


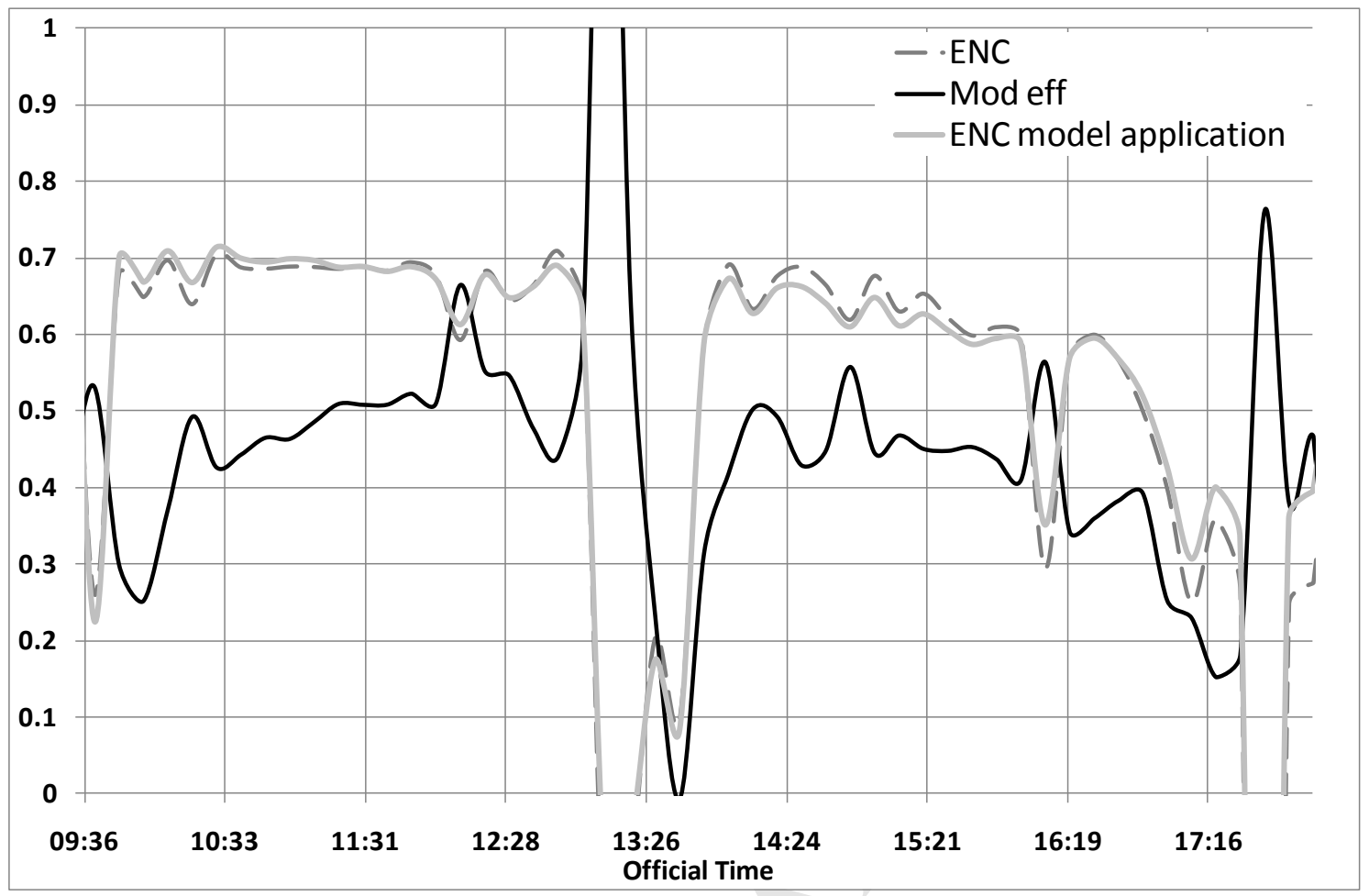

Figure 6: Efficiency of the collector: 'ENC' for ENC, 'Mod eff' for model and 'ENC model application' for the recovery of the values: $\eta_{0}=0.85, K_{\theta B}\left(\theta_{B}\right)=1, K_{\theta D}\left(\theta_{D}\right)=$ 0.82 , thermal inertia effect removed and radiation losses $\left(E_{L}-\sigma T_{a}^{4}\right)=100 \mathrm{~W} \mathrm{~m}^{-2}$, for the central part of the representative day (2009-01-20). 

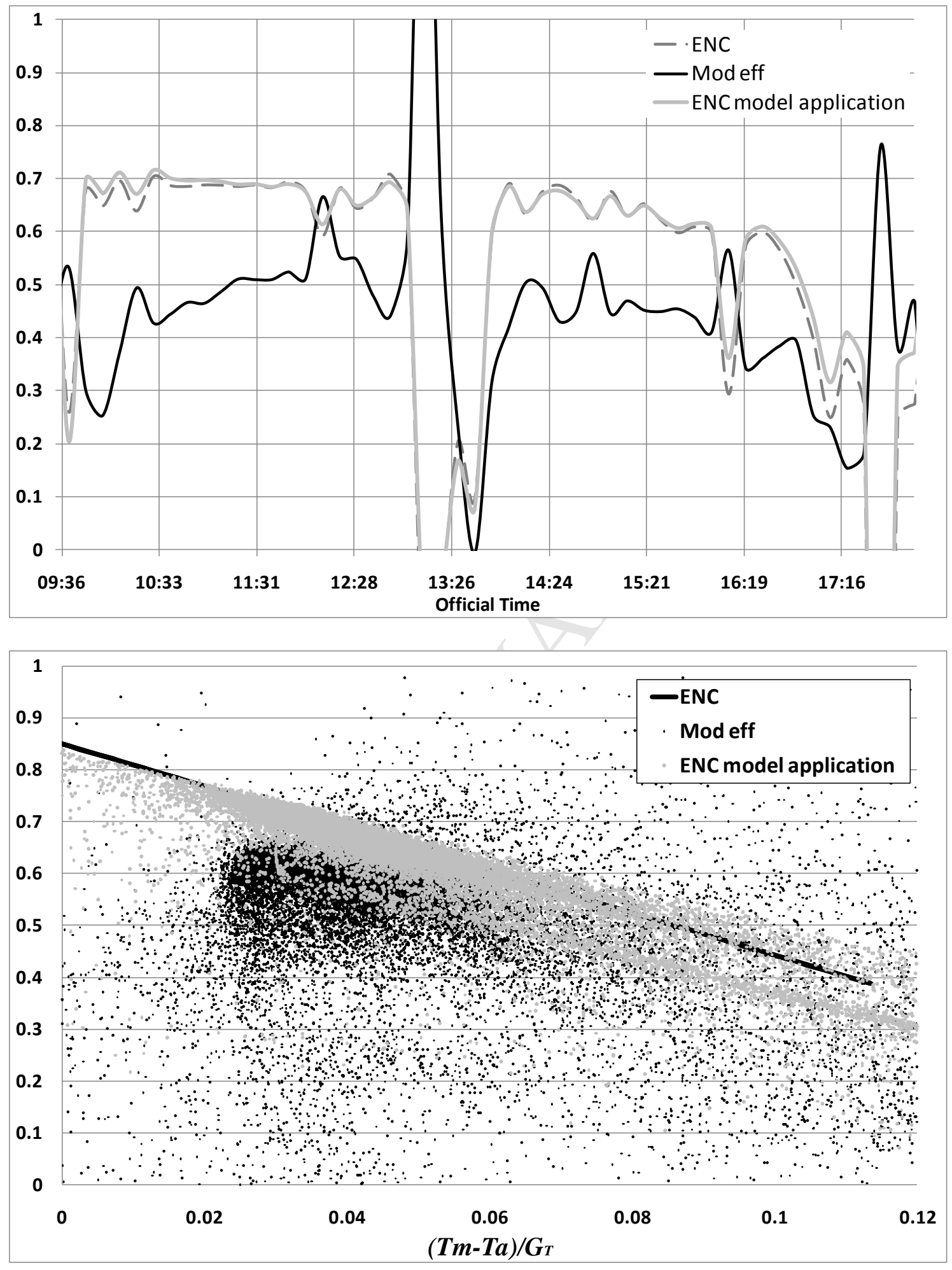

Figure 7: Efficiency of the collector: 'ENC' for ENC, 'Mod eff' for model and 'ENC model application' for the recovery of the values: $\eta_{0}=0.85, K_{\theta B}\left(\theta_{B}\right)=1, K_{\theta D}\left(\theta_{D}\right)=$ 0.82 , thermal inertia effect removed and $\left(E_{L}-\sigma T_{a}{ }^{4}\right)=100 \mathrm{~W} \mathrm{~m}^{-2}, u=3 \mathrm{~m} \mathrm{~s}^{-1}$ and 
a wind direction parallel to the collector surface for the central part of the representative day, 2009-01-20 (above). Working conditions that correspond to an entire year were applied (below). 


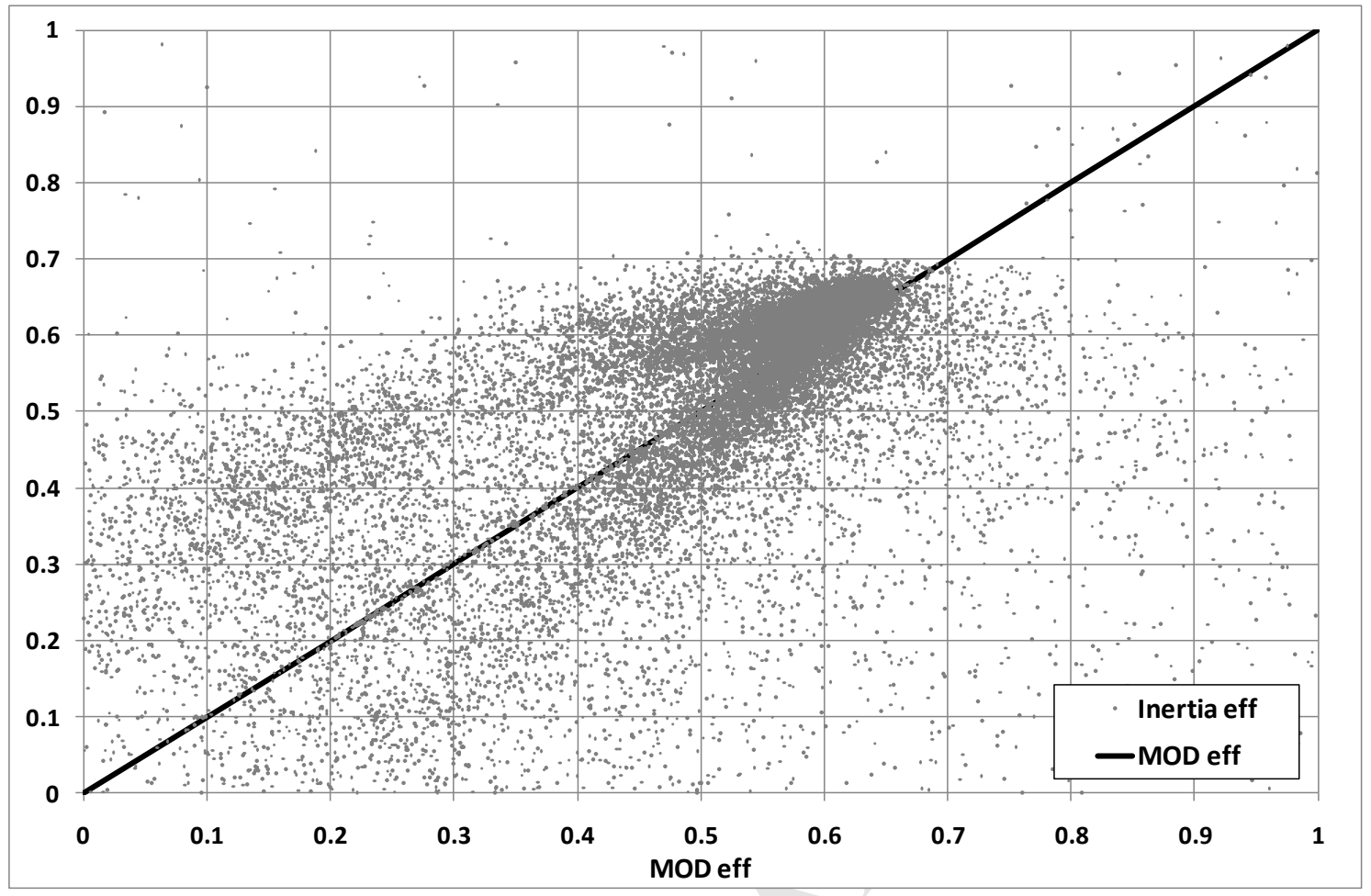

Figure 8: Comparison between the model efficiency as 'MOD eff' and the model efficiency without the thermal inertia effect as 'Inertia eff', applied to the entire year of meteorological data. 


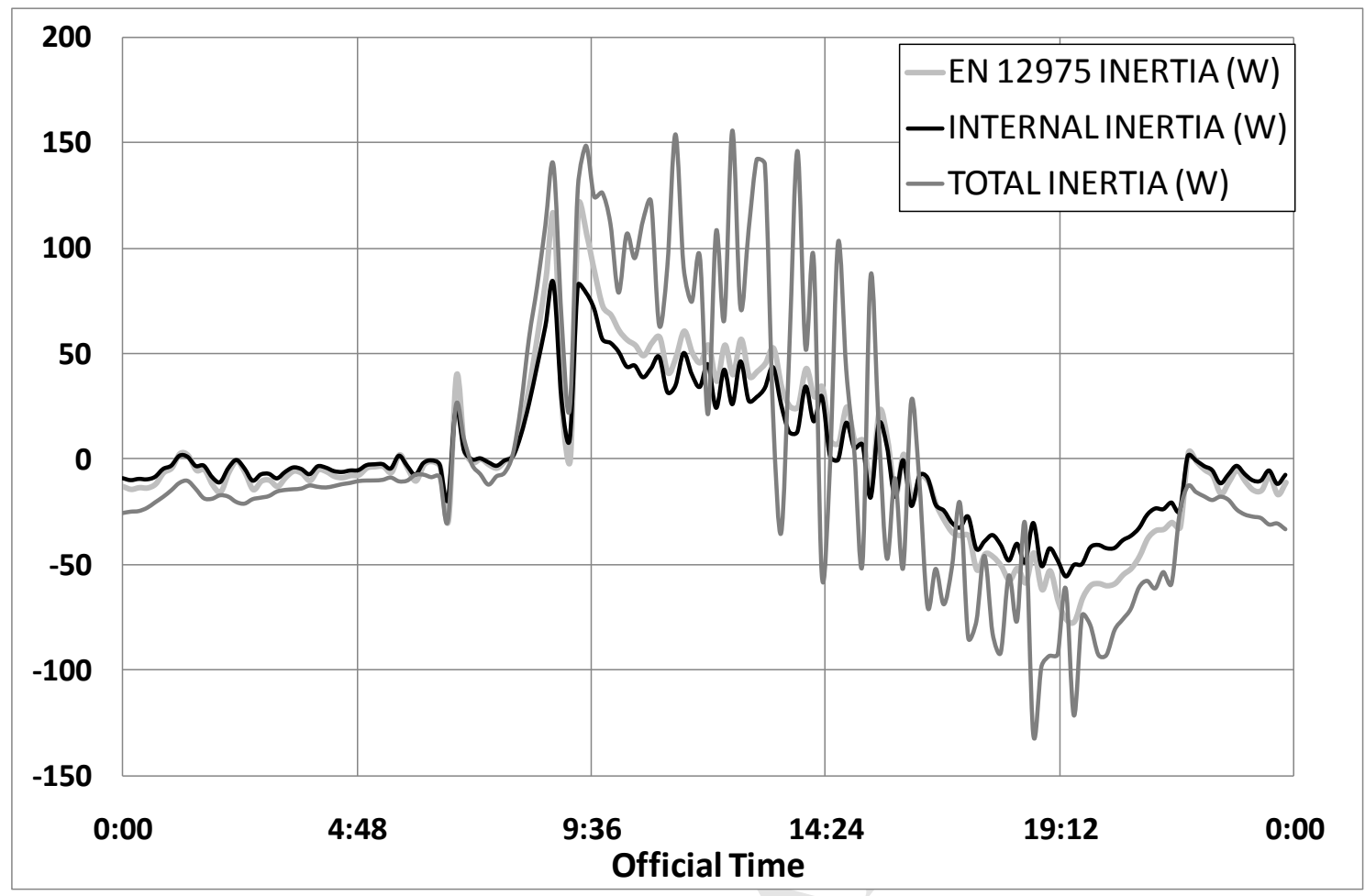

Figure 9: Collector thermal inertia time evolution: for the application of EN-12975:2006 as 'EN-12975 INERTIA', for the model application with all the components as 'TOTAL INERTIA' and including only the absorber plate, inner water and insulation as 'INTERNAL INERTIA', for the central part of the representative day (2009-01-20). 


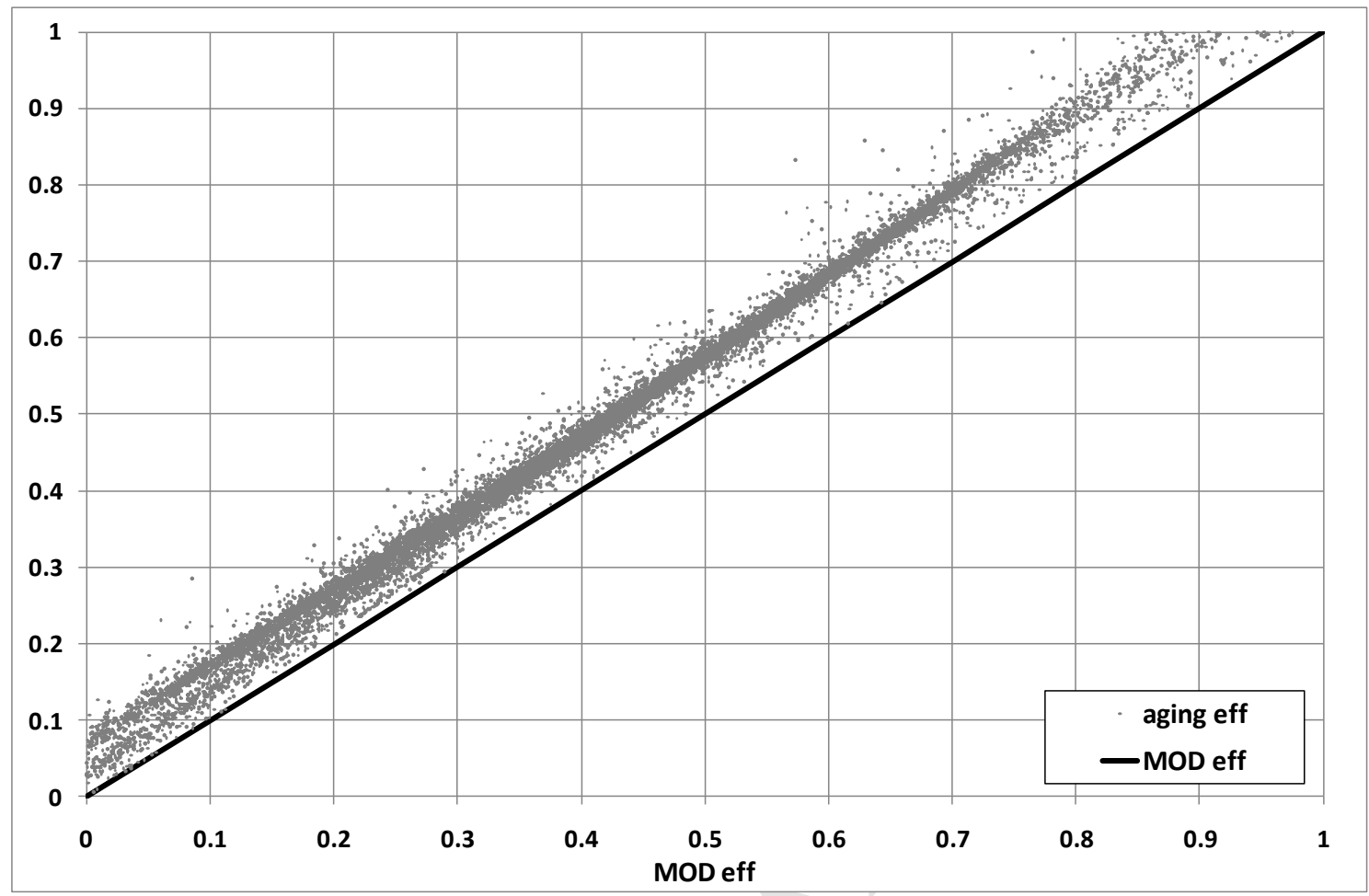

Figure 10: Comparison between the model efficiency without the aging effect as 'aging eff' and the model efficiency as 'MOD eff', applied to the entire year of meteorological data. 


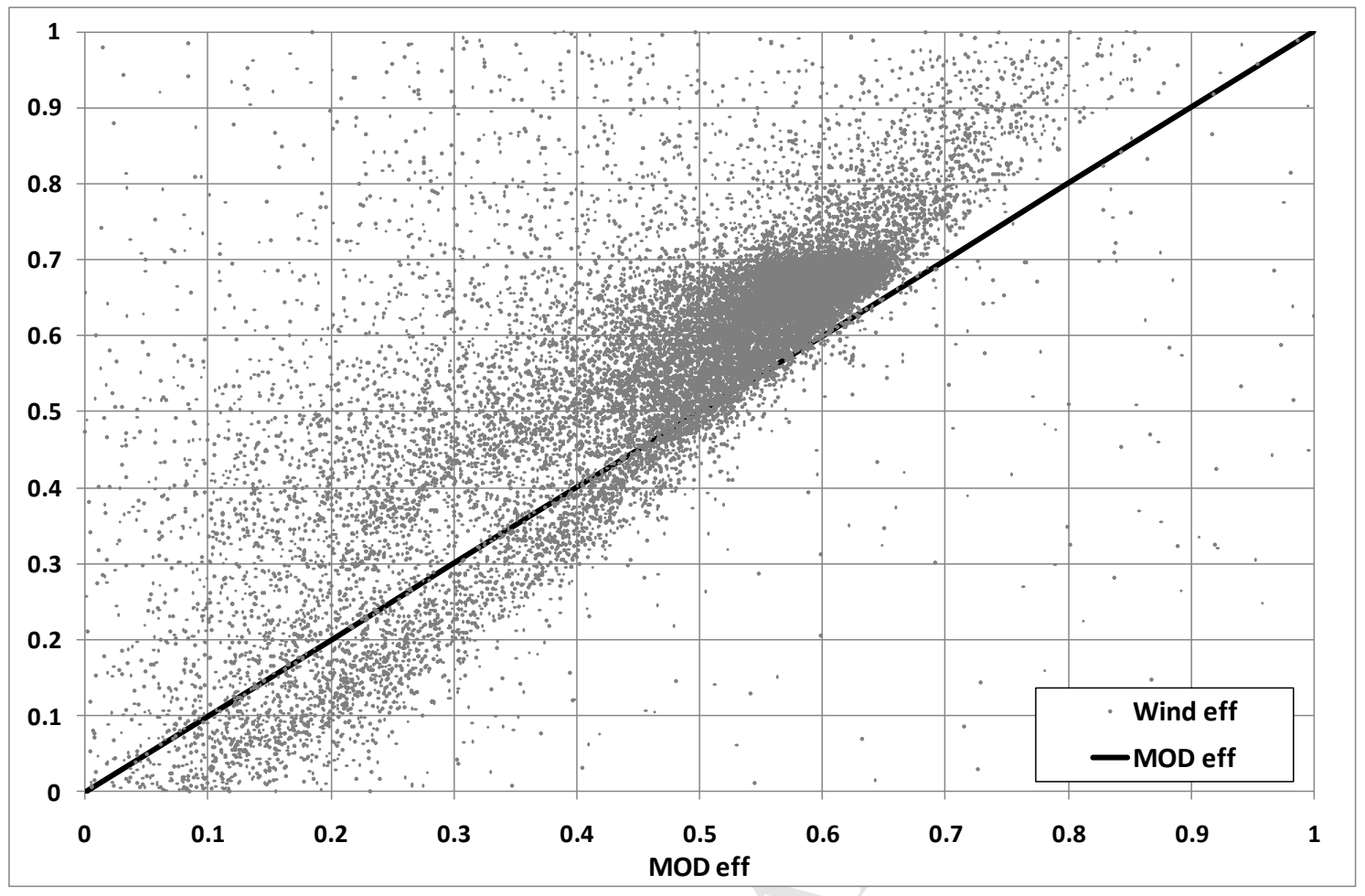

Figure 11: Comparison between the model efficiency as 'MOD eff' and the model efficiency without the wind velocity effect as 'Wind eff', applied to the entire year of meteorological data. 


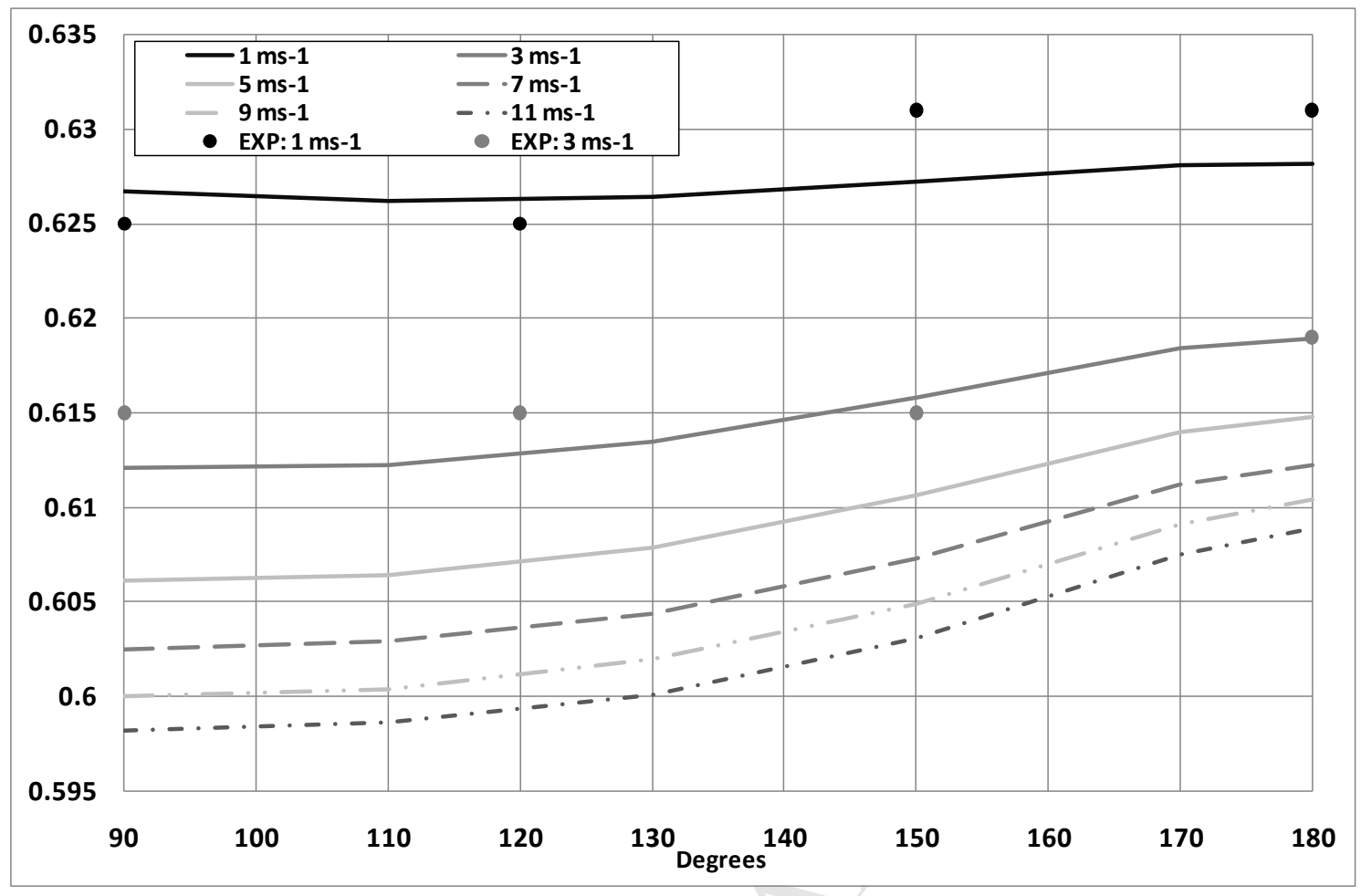

Figure 12: Collector efficiency variation with wind velocity magnitude and direction. The efficiency was calculated by introducing the specified wind magnitude and direction into the model for an actual point with $\left(\frac{T_{m}-T_{a}}{G_{T}}\right)=0.030 \mathrm{~K} \mathrm{~m}^{2} \mathrm{~W}^{-1}, G_{T}=$ $927 \mathrm{~W} \mathrm{~m}^{-2}$ and $\theta_{B}=20 \mathrm{deg}$. The dots represent the actual data as 'EXP'. 


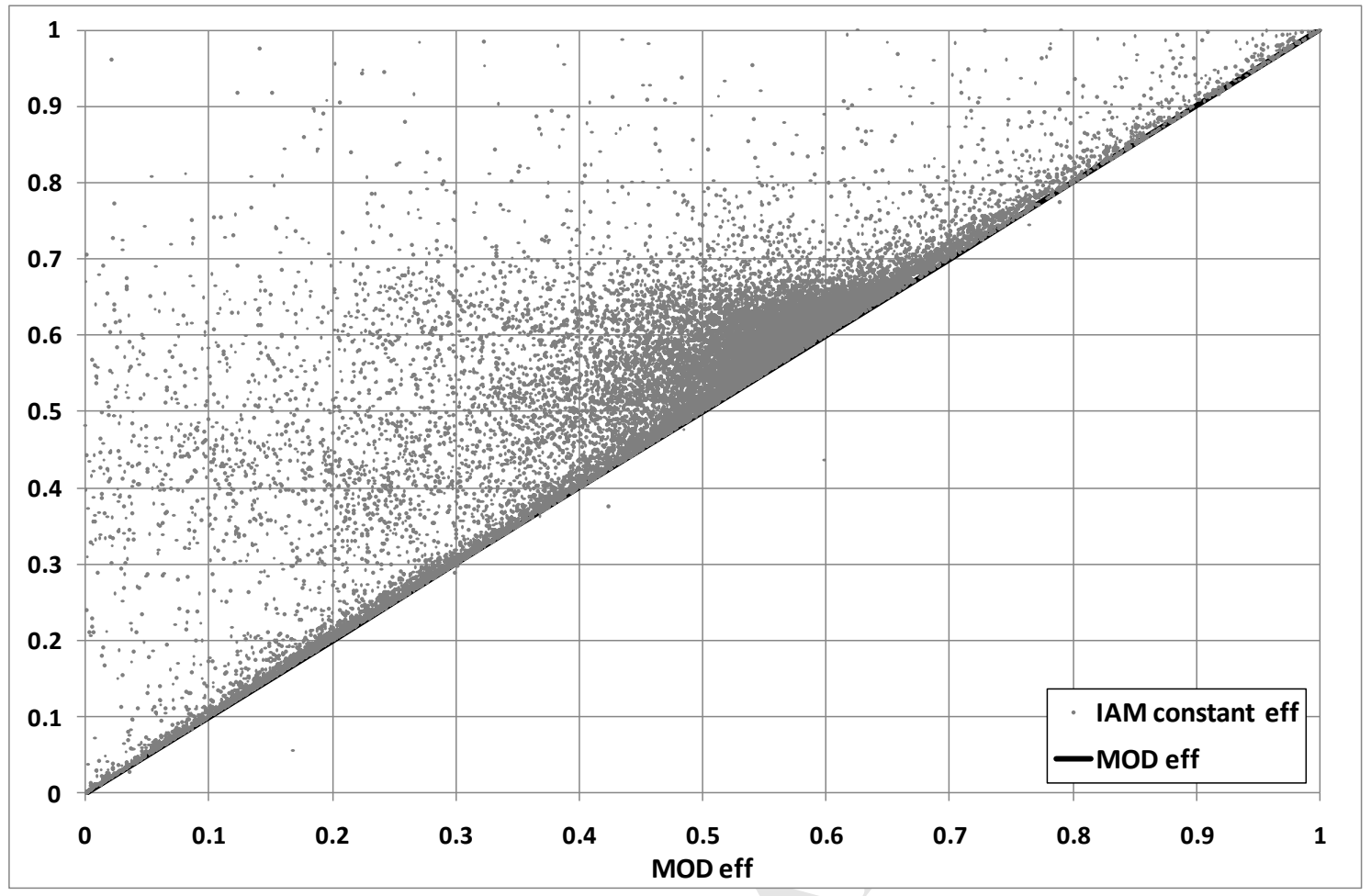

Figure 13: Comparison between the model efficiency as 'MOD eff' and the model efficiency without the IAM effect as 'IAM constant eff', applied to the entire year of meteorological data. 


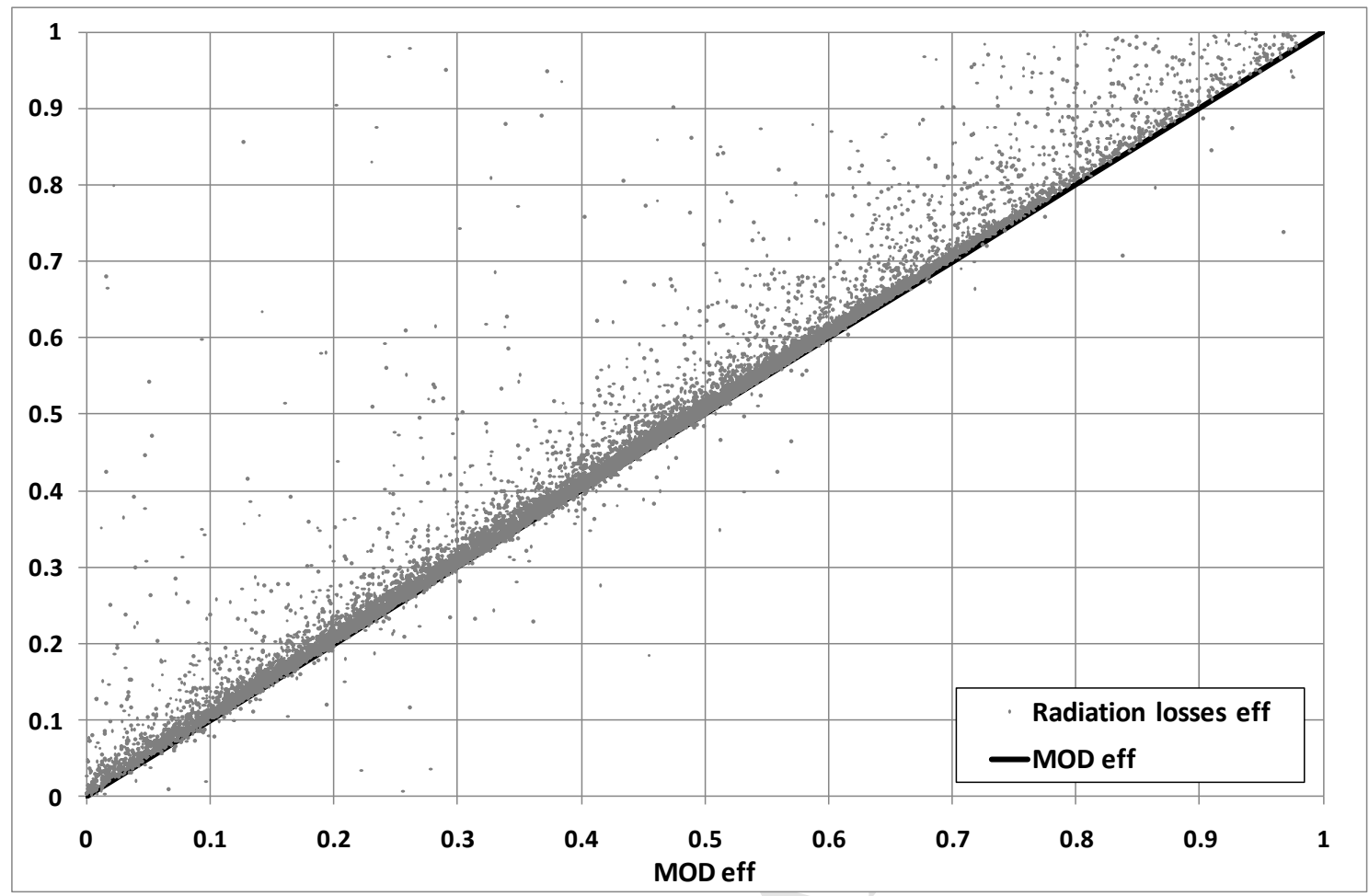

Figure 14: Comparison between the model efficiency as 'MOD eff' and the model efficiency without the radiation losses effect 'Radiation losses eff', applied to the entire year of environmental data. 